\title{
ORGANOID AS A NOVEL TECHNOLOGY FOR DISEASE MODELING
}

\section{Tolga Sever ${ }^{1}$, Ilgin Cevik ${ }^{2,3}$, Gizem Calibasi-Kocal ${ }^{4}$, Yasemin Basbinar ${ }^{4}$, Ender Berat Ellidokuz ${ }^{5}$}

\footnotetext{
${ }^{1}$ Dokuz Eylul University, Institute of Health Sciences, Department of Translational Oncology, Izmir, Turkey

2 Koc High School, Istanbul, Turkey.

${ }^{3}$ Dokuz Eylul University, Institute of Oncology, Department of Translational Oncology, Pre-graduated Research Group, Izmir, Turkey.

${ }^{4}$ Dokuz Eylul University, Institute of Oncology, Department of Translational Oncology, Izmir, Turkey.

${ }^{5}$ Dokuz Eylul University, Faculty of Medicine, Department of Internal Medicine, Department of Gastroenterology, Izmir, Turkey.
}

\author{
Address for Correspondence: Assoc.Prof. Gizem Calibasi-Kocal, E-mail: gizem.calibasi@deu.edu.tr \\ Received: 06.01.2021; Accepted: 08.02.2021; Available Online Date: 04.03.2021 \\ @C Copyright 2021 by Dokuz Eylül University, Institute of Health Sciences - Available online at https://dergipark.org.tr/en/pub/jbachs
}

Cite this article as: Sever T, Cevik I, Calibasi-Kocal G, Basbinar Y, Ellidokuz EB. Organoid as a novel technology for disease modeling. J Basic Clin Health Sci 2021; 1: 94-101.

\begin{abstract}
The organoid technology is capable to create more real-like in vitro models in terms of structure and function of the origin of the tissue. Since the three-dimensional model is able to illustrate disease pathology, cell differentiation, and recapitulation of self-renewal, lead organoid technology as a promising disease model to fill the gap between conventional two-dimensional, and in vivo disease models. The review describes the recent development of organoid disease modeling approaches.
\end{abstract}

Keywords: Organoid, Disease Modeling, Stem Cell

\section{INTRODUCTION}

Disease modeling via animal and cell culture techniques have been providing great contribution in explaining the mechanism of diseases and identifying potential curative approaches. However, there is still a significant lack of models that could show more physiologically and predictive relevant results. Twodimensions (2D) cell cultures have been routinely and ardently used worldwide for the past decades. However, the 2D cell cultures are tenable ancient and do not reflect the physiology or anatomy of the regarding tissues for enlightening studies (1). Moreover, in vivo cancer models have some limitations such as consumption in time and resources, expensiveness, and interspecies differentiation (2).

These limitations have prompted scientists to search for new models that better mimic the parental tissue.
Designing a three-dimension (3D) cell culture model requires multidisciplinary expertise and approach (3). Several 3D cell culture models have been studied up to now such as the spheroid, ex-vivo, and organoid. Organoids, as a novel and promising in vitro culture model, were generated via the self-organizing capacity of stem cells that could recapitulate the function, architecture, genetic signatures of the parental tissue (4). Despite the organoid technology has numerous advantages, the technology has several limitations. Development of vascularization, as one of the obstacles, is crucial for cell-cell and stromal-cell interactions did not occur except several studies in the xenograft model generation process (5). Other limitations of the technology are the lack of microbiota, for the gut model, and the immune system that has slightly solved via co-culture systems $(6,7)$. Another obvious drawback of the technology is the 
absence of interorgan communication since they mimic a specific part of the human body, not the entire. Thus, they could not recapitulate the microphysiology of specific tissue or organ. Several studies have been already focused on the limitation. In a study, various organoids have been connected to investigate the interaction between the pancreas, liver, and gastrointestinal tract (8).

Organoids have been used to search for cancer, genetic disorders, and infectious diseases via directly patient-derived or gene editing of human stem cells. (9) Recently, human patient-derived organoids have been generated that provide a more accurate disease model. A large body of studies shows the great potential of organoid technology in drug screening, drug optimization, regenerative medicine, and personalized medicine (10).

Taken together these pieces of information, in this study, we reviewed the applications and advantages/disadvantages of organoids in several disease models.

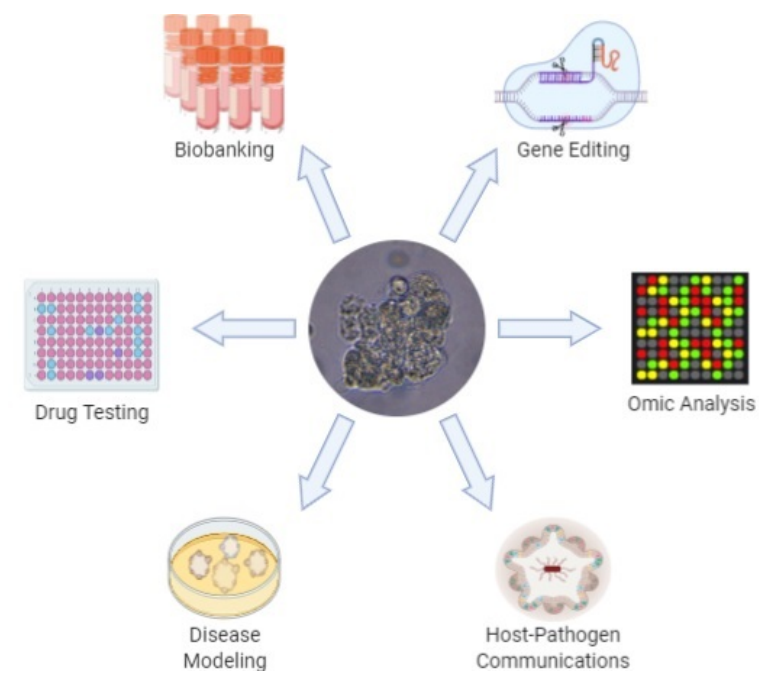

Figure 1. The figure summarizes the application areas of organoid technology and created by using BioRender (https://biorender.com/).

\section{Organoid Modeling for Cancer}

Up to now, vigorous efforts have been done in the cancer research area and important development has been reached in the treatment and diagnosis $(11,12)$. Still, cancer indicates a major health concern globally due to the low life quality and survival of patients with cancer. Since poor mimicking of the parental tumor by traditional cancer models, the progress of efficient therapy is one of the major obstacles which are working on these cancer models lastly fails in clinical practices. The lacks of conventional cancer models are microenvironment, stromal compartments, organspecific function, immune system, genetic heterogeneity $(2,13,14)$. The promising organoid technology bridges the gap between traditional in vitro and in vivo cancer models (15). Tumoroids have been generated from tissue biopsies, surgical resections, ascitic fluid, and circulating tumor cells (16-19). Tumoroids could be used for various downstream implementations since they could be propagated and passaged indefinitely (20). Tumoroids could be an important branch of organoid technology, such as genetic carcinoma, infectioncancer development, and mutation-tumorigenesis processes (21-25). Tumoroids have been generated and bio-banked from various types of primary and metastatic cancers as colorectal, pancreatic, prostate, lung, liver, ovaries, kidney, bladder, brain, cancers, etc. (26).

Nowadays, drug response analysis of patients and their matched tumoroids showed that drug responses are very parallel. In case of drugs did not affect the tumoroids, the matched patient was not affected, and drugs that displayed efficiency in tumoroids were matched by the patient response with $90 \%$ of cases. In several studies, this initial study has been found corroborated $(27,28)$. An accelerated number of studies on patient-derived tumoroids, their molecular profiling, and usage in xenograft formation, may provide more reliable in vitro screening platforms for personalized medicine (29). Analyzed cancer types and sample sizes are limited. Thus, more stringent researches are necessary for routinely adopting patient-derived tumoroids as in vitro patients 'avatars'.

\section{Organoid Models for Neurodegenerative Diseases}

Recently, human brain organoids, generally generated from PSCs, have been used in neuroscience to evaluate mainly neurodevelopmental processes and related disorders. In a study, PSCsderived brain organoids have been utilized to illustrate transcriptional dysregulation and developmental malformations which take place in schizophrenia. Since the organoid technology has 3D brain conformations, the research group could have evaluated the disruptive organoid region of 
Table.1 Applications of organoid technology in disease modeling. The table includes studies about organoid modeling of cancer and genetic, neurodegenerative, and infectious diseases.

\begin{tabular}{|c|c|c|}
\hline Disease Model & Organ & References \\
\hline \multirow{9}{*}{ Cancer } & Bladder & Mullenders et al., 2019(49) \\
\hline & Colorectal & $\begin{array}{l}\text { Yao et al., 2020(50); Schnalzger et al., 2020(51); } \\
\text { Fujii et al., 2016(20); Drost et al., 2015(52) }\end{array}$ \\
\hline & Breast & $\begin{array}{l}\text { Yang et al., 2020(53); Griscelli et al., 2017(54); } \\
\text { Sachs et al.,2018(55) }\end{array}$ \\
\hline & Kidney & $\begin{array}{l}\text { Hwang et al., 2019(56); Wang et al., 2017(57); } \\
\text { Batchelder et al., 2015(58) }\end{array}$ \\
\hline & Ovary & $\begin{array}{l}\text { Nanki et al., 2020(59); Kopper et al., 2019(60); Hill } \\
\text { et al., 2018(19) }\end{array}$ \\
\hline & Lung & $\begin{array}{l}\text { Shi et al., 2020(61); Kim et al., 2019(62); Dijkstra } \\
\text { et al., 2018(63) }\end{array}$ \\
\hline & Liver & Broutier et al., 2017(64) \\
\hline & Brain & $\begin{array}{l}\text { Bhaduri et al., 2020(65); Ballabio et al., 2020(66); } \\
\text { Jacob et al., 2020(67) }\end{array}$ \\
\hline & Prostate & Beshiri et al., 2018(68); Gao et al.,2014(18) \\
\hline \multirow{5}{*}{ Neuroscience } & Malformation & Dunnack et al., 2017(69) \\
\hline & Microencephaly & Gabriel et al., 2020(70); Kelava et al., 2016(71) \\
\hline & Autism/macrocephaly & $\begin{array}{l}\text { Chan et al., 2020(72); Hohmann et al,. 2020(73); } \\
\text { Mariani et al., 2015(74) }\end{array}$ \\
\hline & Alzheimer's disease & Papaspyropoulos et al., 2020(75) \\
\hline & Parkinson's disease & Kim et al., 2021(76); Monzel et al., 2017(77) \\
\hline \multirow{8}{*}{$\begin{array}{l}\text { Genetic } \\
\text { Diseases }\end{array}$} & Familial adenomatous polyposis & Sommer et al., 2018(78); Crespo et al., 2017(79) \\
\hline & Cystic fibrosis & Berkers et al., 2019(80); Dekkers et al., 2013(81) \\
\hline & Alagille syndrome & Guan et al.,2017(82) \\
\hline & Polycystic kidney disease & Freedman et al., 2015(83) \\
\hline & Miller-Dieker lissencephaly syndrome & $\begin{array}{l}\text { Bershteyn et al., 2017(84); lefremova et al., } \\
2017(85)\end{array}$ \\
\hline & Rett syndrome & Gomes et al., 2020(86); Feldman et al., 2016(87); \\
\hline & Timothy syndrome & Sloan et al., 2018(88) \\
\hline & Hereditary multiple intestinal atresia & Bigorgne et al., 2014(89) \\
\hline \multirow{3}{*}{$\begin{array}{l}\text { Infectious } \\
\text { Diseases }\end{array}$} & Brain & Watanabe et al., 2017(90); Gabriel et al., 2017(28) \\
\hline & Intestinal & Lamers et al., 2020(91) \\
\hline & Stomach & Bartfeld et al., 2015(92) \\
\hline
\end{tabular}

schizophrenic patients. The study suggests that organoid technology could be used for such disease models (30). The prenatal hypoxic injury cause early life neurological defects. Since the human corticogenesis evaluation model is lack, all consequences of hypoxia are still not known. The prenatal hypoxic injury cause early life neurological defects. Since the human corticogenesis evaluation model is lack, all consequences of hypoxia are still not known. Daviaud et al. reported the brain organoid model as a starting point to analyze new approaches in therapeutic to regenerate and protect affected cell populations in the neurodevelopmental process (31). Neurodegenerative disease modeling is also applicable as, Parkinson's disease, Fronto-Temporal
Dementia, Alzheimer's disease and Amyotrophic Lateral Sclerosis (32). On the other hand, brain organoids could reflect various sites of the brain such as the midbrain and neocortex. In order to evaluate more complex biological mechanisms in the human brain, Chen et al. generate an organoid model socalled assemboloid which pre-patterned into a specific cite of the brain (33). As a result, brain organoids supply an interesting overview of various ways that could be utilized for neuroscience.

\section{Organoid Models for Genetic Diseases}

Recently revealed CRISPR-Cas9 endonuclease technology provides a genetic engineering method, that readily available to researchers (34). A large 
body of studies performed the gene-editing system on human pluripotent stem cells (hPSCs) in order to generate specific mutated isogenic cell lines. Since different cell lines have strong phenotypical variations, these cell lines have been served as a crucial control for genetic analysis (35). CRISPRCas9 genome editing combined organoid technology enlarges the organoid applications in various ways. Genetic diseases modeled with organoid technology are cystic fibrosis, hereditary multiple intestinal atresias for intestine, familial adenomatous polyposis for colon, alagille syndrome for liver, polycystic kidney disease for kidney, microlissencephaly, miller-dieker lissencephaly syndrome, rett syndrome, timothy syndrome for the brain, enhanced s-cone syndrome, retinitis pigmentosa for the retina, and leber congenital amaurosis (36). As an example, in the Caucasian population, the leading lethal genetic disorder is cystic fibrosis (CF) that is a multiorgan disease including, pancreas, lung, reproductive tract, intestine, and liver (37). In a study of cystic fibrosis, the F508del in cystic fibrosis transmembrane conductance regulator (CFTR) gene that encodes CFTR protein, leading to misfolded CFTR channel protein, mutant human intestinal organoids that cause to fast degradation were corrected via CRISPRCas9. The edited CFTR amino acid sequence displayed a normal channel activity in vitro (38). The study clearly showed that targeted gene therapy could be another application of the organoid technology that has the potential for more accurate targeted gene therapy approaches. Taken together, organoids could be combined with other technologies to create better disease models.

\section{Organoid Models for Infectious Diseases}

The organoid has been accepted as a promising technology for disease modeling that fulfills this expectation more day by day. One of the most important advantages of organoid technology is eliminating the interspecies differences when applied for disease modeling. Additionally, organoids include various cell types present in the parental tissue that could be altered by changing the medium compositions to have interested cell lineages (39). These advantages make the organoid technology amenable to study infectious diseases. Brain organoids are derived from human pluripotent stem cells that self-organize and recapitulate the in vivo fetal brain tissue better than $2 \mathrm{D}$ cell cultures in terms of architecture and composition such as progenitor, glial, and neuronal cell types $(40,41)$.

A myriad study has been focused on the Zika virus (ZIKV), a member of the Flaviviridae family, that transmit to the human being from mosquitos. It has been associated with microcephaly in newborns and possessed a crucial risk for pregnancy (42). The organoid technology has been applied to reveal the mechanism of the infectious since it can reflect the malformation of the brain driven by the ZIKV. In a study, ZIKV-exposed brain organoids show that favored infection of neuronal progenitor cells, which inhibits the proliferation and induces a decrease of cell viability that leads to reduced organoid size (43). Recent studies have been used brain organoid technology in drug screening to preventing and curing ZIKV infection $(44,45)$.

Nowadays the coronavirus disease 2019 (COVID-19) has been affecting a vigorous number of humans. Despite COVID-19 mostly affects the lung, clinical data indicate a growth in both chronic and acute neurological symptoms such as meningitis/encephalitis and persistent fatigue $(46,47)$. In a recent study, COVID-19 infected brain organoids illustrate that the virus damages the choroid plexus epithelium leads to leakage in the blood-brain barrier that prevents immune cells, pathogens, and cytokines into the brain and cerebrospinal fluid (48). Thus, organoid technology is crucial to study host-pathogen interactions via modeling infectious diseases.

\section{CONCLUSION}

Already myriad studies have been declared highly efficient generation of various human diseases modeled with organoid technology. Despite several limitations of this promising and novel 3D technology, the application of the model for understanding the mechanism of diseases and evaluation of more precise therapy options are possible. In order to bring cumulative information produced in the lab to clinical practice fast, the technology is pointed out as a milestone. Still vigorous developmental progress is necessary for the model.

Conflict of Interest: No conflict of interest was declared by the authors

Financial Disclosure: This study was supported by Dokuz Eylul University, Scientific Research Projects (2018.KB.SAG.039).

Peer-review: Externally peer-reviewed. 


\section{REFERENCES}

1. Duval K, Grover H, Han LH, et al. Modeling physiological events in $2 \mathrm{~d}$ vs. $3 \mathrm{~d}$ cell culture. Physiology (bethesda) 2017; 32(4):266-277.

2. Byrne AT, Alférez DG, Amant F, et al. Interrogating open issues in cancer precision medicine with patient-derived xenografts. Nat Rev Cancer 2017; 17(4):254-268.

3. Haycock JW. 3D cell culture: a review of current approaches and techniques. Methods Mol Biol 2011; 695:1-15.

4. Mahe MM, Aihara E, Schumacher MA, et al. Establishment of gastrointestinal epithelial organoids. Curr Protoc Mouse Biol 2013; 3(4):217240.

5. Takebe T, Zhang RR, Koike H, et al. Generation of a vascularized and functional human liver from an iPSC-derived organ bud transplant. Nat Protoc 2014; 9(2):396-409.

6. Schreurs RRCE, Baumdick ME, Sagebiel AF, et al. Human fetal tnf-a-cytokine-producing cd4+ effector memory $T$ cells promote intestinal development and mediate inflammation early in life. Immunity 2019; 50(2):462-476.

7. Noel G, Baetz NW, Staab JF, et al. A primary human macrophage-enteroid co-culture model to investigate mucosal gut physiology and hostpathogen interactions. Sci Rep 2017; 7:45270.

8. Koike H, Iwasawa K, Ouchi R, et al. Modelling human hepato-biliary-pancreatic organogenesis from the foregut-midgut boundary. Nature 2019; 574(7776):112-116.

9. Fujii M, Matano M, Nanki K, Sato T. Efficient genetic engineering of human intestinal organoids using electroporation. Nat Protoc 2015; 10(10):1474-1485.

10. Dutta D, Heo I, Clevers H. Disease modeling in stem cell-derived $3 \mathrm{~d}$ organoid systems. Trends Mol Med 2017; 23(5):393-410.

11. Liu B, Song Y, Liu D. Recent development in clinical applications of PD-1 and PD-L1 antibodies for cancer immunotherapy. J Hematol Oncol 2017; 10(174).

12. Pang $Y$, Hou $X$, Yang $C$, Liu $Y$, Jiang G. Advances on chimeric antigen receptor-modified t-cell therapy for oncotherapy. Mol Cancer 2018; 17(1):91.

13. Zhou J, Su J, Fu X, Zheng L, Yin Z. Microfluidic device for primary tumor spheroid isolation. Exp Hematol Oncol 2017; 6:22.
14. Ben-David U, Ha G, Tseng YY, et al. Patientderived xenografts undergo mouse-specific tumor evolution. Nat Genet 2017; 49(11):15671575.

15. Na JC, Kim JH, Kim SY, et al. Establishment of patient-derived three-dimensional organoid culture in renal cell carcinoma. Investig Clin Urol 2020; 61(2):216-223.

16. van de Wetering M, Francies HE, Francis JM, et al. Prospective derivation of a living organoid biobank of colorectal cancer patients. Cell 2015; 161(4):933-945.

17. Weeber $F$, van de Wetering $M$, Hoogstraat $M$, et al. Preserved genetic diversity in organoids cultured from biopsies of human colorectal cancer metastases. Proc Natl Acad Sci U S A 2015; 112(43):13308-13311.

18. Gao D, Vela I, Sboner A, et al. Organoid cultures derived from patients with advanced prostate cancer. Cell 2014; 159(1):176-187.

19. Hill SJ, Decker B, Roberts EA, et al. Prediction of DNA Repair Inhibitor Response in Short-Term Patient-Derived Ovarian Cancer Organoids. Cancer Discov 2018; 8(11):1404-1421.

20. Fujii M, Shimokawa M, Date S, et al. A colorectal tumor organoid library demonstrates progressive loss of niche factor requirements during tumorigenesis. Cell Stem Cell 2016; 18(6):827838.

21. Yeung TM, Gandhi SC, Wilding JL, Muschel R, Bodmer WF. Cancer stem cells from colorectal cancer-derived cell lines. Proc Natl Acad Sci U S A 2010; 107(8):3722-3727.

22. Onuma K, Ochiai M, Orihashi K, et al. Genetic reconstitution of tumorigenesis in primary intestinal cells. Proc Natl Acad Sci U S A 2013; 110(27):11127-11132.

23. Matano M, Date S, Shimokawa M, et al. Modeling colorectal cancer using CRISPR-Cas9-mediated engineering of human intestinal organoids. Nat Med 2015; 21(3):256-262.

24. Scanu T, Spaapen RM, Bakker JM, et al. Salmonella manipulation of host signaling pathways provokes cellular transformation associated with gallbladder carcinoma. Cell Host Microbe 2015; 17(6):763-774.

25. Davies H, Glodzik D, Morganella $S$, et al. HRDetect is a predictor of BRCA1 and BRCA2 deficiency based on mutational signatures. Nat Med 2017; 23(4):517-525. 
26. Driehuis E, Kretzschmar K, Clevers $H$ Establishment of patient-derived cancer organoids for drug-screening applications. Nat Protoc 2021; 15(10):3380-3409.

27. Vlachogiannis $G$, Hedayat S, Vatsiou $A$, et al. Patient-derived organoids model treatment response of metastatic gastrointestinal cancers. Science 2018; 359(6378):920-926.

28. Ganesh K, Wu C, O'Rourke KP, et al. A rectal cancer organoid platform to study individual responses to chemoradiation. Nat Med 2019; 25(10):1607-1614.

29. Yoshida GJ. Applications of patient-derived tumor xenograft models and tumor organoids. J Hematol Oncol 2020; 13(1):4.

30. Benson CA, Powell HR, Liput M, et al. Immune factor, TNFa, disrupts human brain organoid development similar to schizophreniaschizophrenia Increases developmental vulnerability to TNFa. Front Cell Neurosci 2020; $14: 233$.

31. Daviaud N, Chevalier C, Friedel RH, Zou $H$. Distinct vulnerability and resilience of human neuroprogenitor subtypes in cerebral organoid model of prenatal hypoxic injury. Front Cell Neurosci 2019; 13:336.

32. Simmnacher K, Lanfer J, Rizo T, Kaindl J, Winner B. Modeling cell-cell Interactions in parkinson's disease using human stem cell-based models. front cell neurosci 2020; 13:571.

33. Chen A, Guo Z, Fang L, Bian S. Application of fused organoid models to study human brain development and neural disorders. Front Cell Neurosci 2020; 14:133.

34. Cong L, Ran FA, Cox D, et al. Multiplex genome engineering using CRISPR/Cas systems. Science 2013; 339(6121):819-823.

35. Zou X, Owusu M, Harris R, Jackson SP, Loizou JI, Nik-Zainal S. Validating the concept of mutational signatures with isogenic cell models. Nat Commun 2018; 9(1):1744.

36. Perez-Lanzon M, Kroemer G, Maiuri MC. Organoids for modeling genetic diseases. Int Rev Cell Mol Biol 2018; 337:49-81.

37. De Boeck K, Vermeulen F, Dupont L. The diagnosis of cystic fibrosis. Presse Med 2017; 46(6 Pt 2):e97-e108.

38. Schwank G, Koo BK, Sasselli V, et al. Functional repair of CFTR by CRISPR/Cas 9 in intestinal stem cell organoids of cystic fibrosis patients. Cell Stem Cell 2013; 13(6):653-658.
39. Artegiani B, Clevers H. Use and application of 3Dorganoid technology. Hum Mol Genet 2018; 27(2):99-107.

40. Jo J, Xiao $Y$, Sun $A X$, et al. Midbrain-like organoids from human pluripotent stem cells contain functional dopaminergic and neuromelanin-producing neurons. Cell Stem Cell 2016; 19(2):248-257.

41. Paşca AM, Sloan SA, Clarke LE, et al. Functional cortical neurons and astrocytes from human pluripotent stem cells in 3D culture. Nat Methods 2015; 12(7):671-678.

42. Hossein F. An overview of the current medical literature on Zika virus. Biophys Rev 2020; 12(5):1133-1138.

43. Qian X, Nguyen HN, Jacob F, Song H, Ming GL. Using brain organoids to understand Zika virusinduced microcephaly. Development 2017; 144(6):952-957.

44. Xu M, Lee EM, Wen Z, et al. Identification of small-molecule inhibitors of Zika virus infection and induced neural cell death via a drug repurposing screen. Nat Med 2016; 22(10):11011107.

45. Zhou T, Tan L, Cederquist GY, et al. High-content screening in hPSC-neural progenitors identifies drug candidates that inhibit Zika virus infection in fetal-like organoids and adult brain. Cell Stem Cell 2017; 21(2):274-283.

46. Moriguchi T, Harii N, Goto J, et al. A first case of meningitis/encephalitis associated with SARSCoronavirus-2. Int J Infect Dis 2020; 94:55-58.

47. Montalvan V, Lee J, Bueso T, De Toledo J, Rivas K. Neurological manifestations of COVID-19 and other coronavirus infections: A systematic review. Clin Neurol Neurosurg 2020; 194:105921.

48. Pellegrini L, Albecka A, Mallery DL, Kellner MJ, Paul D, Carter AP, et al. SARS-CoV-2 infects the brain choroid plexus and disrupts the blood-csf barrier in human brain organoids. Cell Stem Cell 2020; 27(6): 951-961.

49. Mullenders J, de Jongh E, Brousali A, et al. Mouse and human urothelial cancer organoids: $A$ tool for bladder cancer research. Proc Natl Acad Sci USA 2019; 116(10):4567-4574.

50. Yao Y, Xu X, Yang L, et al. Patient-derived organoids predict chemoradiation responses of locally advanced rectal cancer. Cell Stem Cell 2020; 26(1):17-26.

51. Schnalzger TE, de Groot MH, Zhang C, et al. 3D model for CAR-mediated cytotoxicity using 
patient-derived colorectal cancer organoids. EMBO J 2019; 38(12):e100928.

52. Drost J, van Jaarsveld RH, Ponsioen B, et al. Sequential cancer mutations in cultured human intestinal stem cells. Nature 2015; 521(7550):4347.

53. Yang L, Liu B, Chen $\mathrm{H}$, et al. Progress in the application of organoids to breast cancer research. J Cell Mol Med 2020; 24(10):54205427.

54. Griscelli F, Oudrhiri N, Feraud O, et al. Generation of induced pluripotent stem cell (iPSC) line from a patient with triple negative breast cancer with hereditary exon 17 deletion of BRCA1 gene. Stem Cell Res 2017; 24:135-138.

55. Sachs N, de Ligt J, Kopper O, et al. A living biobank of breast cancer organoids captures disease heterogeneity. Cell 2018; 172(1-2):373386.

56. Hwang JW, Desterke C, Féraud O, et al. IPSCderived cancer organoids recapitulate genomic and phenotypic alterations of c-met-mutated hereditary kidney cancer. BioRxiv 2019. DOI: $10.1101 / 518456$

57. Wang S, Gao D, Chen Y. The potential of organoids in urological cancer research. Nat Rev Urol 2017; 14(7):401-414.

58. Batchelder CA, Martinez ML, Duru N, Meyers FJ, Tarantal AF. Three dimensional culture of human renal cell carcinoma organoids. PLoS One 2015; 10(8):e0136758.

59. Nanki $Y$, Chiyoda T, Hirasawa A, et al. Patientderived ovarian cancer organoids capture the genomic profiles of primary tumours applicable for drug sensitivity and resistance testing. Sci Rep 2020; 10(1):12581.

60. Kopper O, de Witte CJ, Lõhmussaar K, et al. An organoid platform for ovarian cancer captures intra- and interpatient heterogeneity. Nat Med 2019; 25(5):838-849.

61. Shi R, Radulovich $\mathrm{N}, \mathrm{Ng} \mathrm{C}$, et al. Organoid cultures as preclinical models of non-small cell lung cancer. Clin Cancer Res 2020; 26(5):11621174

62. Kim M, Mun H, Sung CO, et al. Patient-derived lung cancer organoids as in vitro cancer models for therapeutic screening. Nat Commun 2019; 10(1):3991.

63. Dijkstra KK, Cattaneo CM, Weeber F, et al. Generation of tumor-reactive T cells by co-culture of peripheral blood lymphocytes and tumor organoids. Cell 2018; 174(6):1586-1598.

64. Broutier L, Mastrogiovanni G, Verstegen MM, et al. Human primary liver cancer-derived organoid cultures for disease modeling and drug screening. Nat Med 2017; 23(12):1424-1435.

65. Bhaduri A, Andrews MG, Mancia Leon W, et al. Cell stress in cortical organoids impairs molecular subtype specification. Nature 2020; 578(7793):142-148.

66. Ballabio $C$, Anderle $M$, Gianesello $M$, et al. Modeling medulloblastoma in vivo and with human cerebellar organoids. Nat Commun 2020; 11(1):583.

67. Jacob F, Salinas RD, Zhang DY, et al. A patientderived glioblastoma organoid model and biobank recapitulates inter- and intra-tumoral heterogeneity. Cell 2020; 180(1):188-204.

68. Beshiri ML, Tice CM, Tran C, et al. A PDX/organoid biobank of advanced prostate cancers captures genomic and phenotypic heterogeneity for disease modeling and therapeutic screening. Clin Cancer Res 2018; 24(17):4332-4345.

69. Dunnack JJ, LoTurco JJ. Of Mice and Men: Species-specific organoid models of neocortical malformation. Cell Stem Cell 2017; 20(4):421422.

70. Gabriel E, Ramani A, Altinisik N, Gopalakrishnan J. Human brain organoids to decode mechanisms of microcephaly. Front Cell Neurosci 2020; 14:115.

71. Kelava I, Lancaster MA. Stem cell models of human brain development. Cell Stem Cell 2016; 18(6):736-748.

72. Chan WK, Griffiths R, Price DJ, Mason JO. Cerebral organoids as tools to identify the developmental roots of autism. Mol Autism 2020; 11(1):58.

73. Hohmann SS, llieva M, Michel TM. In vitro models for ASD-patient-derived iPSCs and cerebral organoids. Prog Mol Biol Transl Sci 2020; 173:355-375.

74. Mariani J, Coppola G, Zhang P, et al. FOXG1dependent dysregulation of gaba/glutamate neuron differentiation in autism spectrum disorders. Cell 2015; 162(2):375-390.

75. Papaspyropoulos A, Tsolaki M, Foroglou N, Pantazaki AA. Modeling and targeting alzheimer's disease with organoids. Front Pharmacol 2020; 11:396. 
76. Kim SJ, Li J, Mahairaki V. Stem cell-derived threedimensional (organoid) models of Alzheimer's disease: a precision medicine approach. Neural Regen Res 2021; 16(8):1546-1547.

77. Monzel AS, Smits LM, Hemmer K, et al. Derivation of human midbrain-specific organoids from neuroepithelial stem cells. stem cell reports 2017; 8(5):1144-1154.

78. Sommer CA, Capilla A, Molina-Estevez FJ, et al. Modeling APC mutagenesis and familial adenomatous polyposis using human iPS cells. PLoS One 2018; 13(7):e0200657.

79. Crespo M, Vilar E, Tsai SY, et al. Colonic organoids derived from human induced pluripotent stem cells for modeling colorectal cancer and drug testing [published correction appears in Nat Med. 2018 Apr 10;24(4):526]. Nat Med 2017; 23(7):878-884.

80. Berkers G, van Mourik P, Vonk AM, et al. Rectal organoids enable personalized treatment of cystic fibrosis. Cell Rep 2019; 26(7):1701-1708.

81. Dekkers JF, Wiegerinck CL, de Jonge HR, et al. A functional CFTR assay using primary cystic fibrosis intestinal organoids. Nat Med 2013; 19(7):939-945.

82. Guan $Y, X u D$, Garfin PM, et al. Human hepatic organoids for the analysis of human genetic diseases. JCI Insight 2017; 2(17):e94954.

83. Freedman BS, Brooks CR, Lam AQ, et al. Modelling kidney disease with CRISPR-mutant kidney organoids derived from human pluripotent epiblast spheroids. Nat Commun 2015; 6:8715.

84. Bershteyn M, Nowakowski TJ, Pollen AA, et al. Human iPSC-derived cerebral organoids model cellular features of lissencephaly and reveal prolonged mitosis of outer radial glia. Cell Stem Cell 2017; 20(4):435-449.

85. lefremova $V$, Manikakis $G$, Krefft $O$, et al. An Organoid-based model of cortical development identifies non-cell-autonomous defects in wnt signaling contributing to miller-dieker syndrome. Cell Rep 2017; 19(1):50-59.

86. Gomes AR, Fernandes TG, Vaz SH, et al. Modeling rett syndrome with human patientspecific forebrain organoids. Front Cell Dev Biol 2020; 8:610427.

87. Feldman D, Banerjee A, Sur M. Developmental dynamics of rett syndrome. Neural Plast 2016; 2016:6154080.

88. Sloan SA, Andersen J, Pașca AM, Birey F, Pașca SP. Generation and assembly of human brain region-specific three-dimensional cultures. Nat Protoc 2018; 13(9):2062-2085.

89. Bigorgne AE, Farin HF, Lemoine R, et al. TTC7A mutations disrupt intestinal epithelial apicobasal polarity. J Clin Invest 2014; 124(1):328-337.

90. Watanabe M, Buth JE, Vishlaghi N, et al. Selforganized cerebral organoids with humanspecific features predict effective drugs to combat Zika virus infection. Cell Rep 2017; 21(2):517532.

91. Lamers MM, Beumer J, van der Vaart J, et al. SARS-CoV-2 productively infects human gut enterocytes. Science 2020; 369(6499):50-54.

92. Bartfeld S, Clevers H. Organoids as model for Infectious diseases: culture of human and murine stomach organoids and microinjection of Helicobacter Pylori. J Vis Exp 2015; (105):53359. 